Revue bibliographique pour le domaine irano-aryen

Volume 37-38-39 | 2018

Comptes rendus des publications de 2014-2016

\title{
Hadi Seif. Persian Painted Tile Work from the 18th and 19th Centuries. The Shiraz School
}

\section{Sandra Aube}

\section{(2) OpenEdition \\ 12 Journals}

\section{Édition électronique}

URL : http://journals.openedition.org/abstractairanica/42749

DOI : 10.4000/abstractairanica.42749

ISBN : 1961-960X

ISSN : 1961-960X

Éditeur :

CNRS (UMR 7528 Mondes iraniens et indiens), Éditions de l'IFRI

Référence électronique

Sandra Aube, «Hadi Seif. Persian Painted Tile Work from the 18th and 19th Centuries. The Shiraz School », Abstracta Iranica [En ligne], Volume 37-38-39 | 2018, document 18, mis en ligne le 10 mars 2018, consulté le 02 octobre 2020. URL : http://journals.openedition.org/abstractairanica/42749 ; DOI : https://doi.org/10.4000/abstractairanica.42749

Ce document a été généré automatiquement le 2 octobre 2020.

Tous droits réservés 


\title{
Hadi Seif. Persian Painted Tile Work from the 18th and 19th Centuries. The Shiraz School
}

\author{
Sandra Aube
}

\section{RÉFÉRENCE}

Hadi Seif. Persian Painted Tile Work from the 18th and 19th Centuries. The Shiraz School, Stuttgart, Arnoldsche Art Publishers, 2014, 111 p., nombreuses ill. couleur. ISBN: 978-3-89790-403-3

1 Près de vingt ans après la publication de son premier opus (Persian Painted Tiles, Téhéran, c. 1995), Hadi Seif propose un nouveau volume, qu'il justifie par les nombreuses découvertes faites depuis son premier ouvrage (p. 10). Le sujet abordé est d'un intérêt tout particulier tant il est peu souvent traité. La céramique architecturale est, dans son ensemble, relativement peu étudiée. Cette thématique appliquée à l'histoire de Shirāz aux périodes zand et qājāre s'avère combler un manque important dans l'histoire de l'art de l'Iran. L'auteur entreprend ainsi une ambitieuse et nécessaire histoire de la céramique architecturale iranienne depuis la seconde moitié du XVIII ${ }^{\mathrm{e}}$ siècle jusqu'à la première moitié du $\mathrm{XX}^{\mathrm{e}}$ siècle.

2 Seif organise son propos en cinq parties, qui visent à présenter l'évolution chronologique de cette production: "The Beginning of the Tile Making Movement during the Rule of Karim Khan Zand (AD 1750-1779)» (p. 24-35) ; « The Continuation of the Production of Painted Haft Rang Tiles during the Qajar Dynasty (AD 1794-1925) » (p. 36-39) ; "The New Life of Decorative Art and the Rebirth of Painted Tile Work during the Asr Bidari (c. AD 1880-1910)» (p. 41-59) ; «The Appearance of Mirza Abdol Razzogh, Famous Tile Maker from Shiraz, and the Continuation of This Popular Movement under His Leadership » (p. 60-85); et « A Historical Shipwreck. The Popular 
Haft Rang Tiles Go Out of Fashion during rge First Half of the 20th Century AD » (p. 80-99).

Il est intéressant que l'auteur ait porté l'accent sur certains maîtres (Mirzā Aqā Bozorg, les familles Nāser al-Molk ou Qavām al-Molk, par exemple). On notera notamment l'attention accordée au maître Mirzā 'Abd al-Razzāq, qui est en fin de compte l'objet d'une large partie de ce livre. Seif tente de retracer l'histoire de ces artisans, de pointer les relations qui liaient certains d'entre eux, et cherche à quelques reprises à décrypter les caractéristiques stylistiques de certains maîtres.

On regrette cependant que l'analyse historique et technique reste trop concise et superficielle. Au-delà d'approximations historiques, l'auteur ne cite jamais ses sources et sa bibliographie finale est des plus succinctes (13 références en tout et pour tout!). Une mise en perspective de ces céramiques avec les monuments pour lesquels elles ont été créées aurait par ailleurs été bénéfique à cette étude. On regrette également que les céramiques ne fassent pas l'objet d'une analyse technique (hormis une simple présentation des oxydes utilisés, p. 30). Nous nous devons enfin de pointer un problème de vocabulaire d'importance. L'auteur emploi le terme de « Haft rang » (persan, « sept couleurs ») pour désigner ce qu'il définit (p. 104) comme des céramiques peintes sous glaçure. Or, le persan haft rang est l'équivalent chez les chercheurs occidentaux des décors polychromes sur glaçure dits à « ligne noire » (angl. « black line »), anciennement appelés "cuerda seca » et plus récemment " "cloisonné" coloured glaze tiles ». Le terme haft rang a parfois été utilisé dans les publications occidentales mais pour désigner une toute autre technique: celle des minā’i (i.e. des décors de petit feu, sur glaçure). En somme, l'emploi par Seif du terme haft rang engendre ici bien des confusions. Celles-ci sont d'autant plus importantes que les décors présentés par l'auteur sont apparemment essentiellement des décors dits à « ligne noire ", sur glaçure, et non des décors peints sous glaçure comme l'annonce Seif en définition.

Le livre de Seif est néanmoins doté d'une riche iconographie, pour laquelle on aurait certes sans doute apprécié des légendes plus détaillées, mais qui constituera néanmoins un outil d'approche intéressant pour quiconque s'intéresse à l'art de la céramique architecturale et/ou à l'art des périodes zand et qājāre.

\section{AUTEURS}

\section{SANDRA AUBE}

CNRS, Mondes iranien et indien, Paris 